The principle of equivalence and the future

\section{of mental health care in prisons}

\author{
SIMON WILSON
}

In March 1999 the British Government published The Future Organisation of Prison Health Care, setting out the arrangements for a formal partnership between the Prison Service and the National Health Service (HM Prison Service \& NHS Executive, 1999). On 1 April 2003, the NHS formally took over the provision of health care within the 138 prisons in England and Wales. For many years there have been vocal criticisms of the standard of care in prisons (Smith, 1984). Are things about to change?

\section{EQUIVALENCE OF CARE}

The Government's policy for prison health is enshrined in the principle of 'equivalence of care' (Home Office, 1990, 1991; HM Prison Service \& NHS Executive, 1999). Prisoners should receive the same level of health care as they would were they not in prison-equivalent in terms of policy, standards and delivery (Health Advisory Committee for the Prison Service, 1997). The prison population is conceptualised as a community and the health care provided within prison should be equivalent to primary care in the NHS, including specialist out-patient services. Any prisoner requiring more than primary care is to be transferred from prison to hospital to receive it.

Prisons contain large numbers of prisoners with serious mental illnesses (Singleton et al, 1998). The developing prison psychiatric in-reach teams provide a clinical service to two main areas within the prison: the residential population on ordinary location, including in segregation; and the population contained in prison health care wings. The first area is not problematic conceptually for the community/ primary care model and advances have been made in the successful supervision of prisoners with mental disorders on ordinary location - for example, with regular input from psychiatric nursing, monitoring compliance with medication and beginning to implement the care programme approach.

The National Service Framework for Mental Health (Department of Health, 1999) details principles and standards for the provision of psychiatric care:

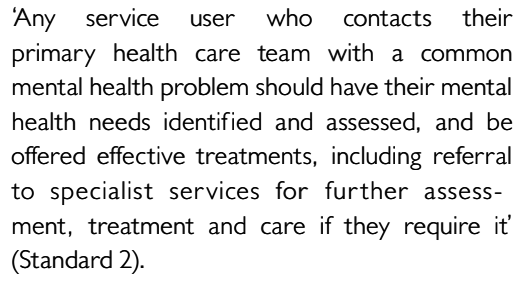

This already happens in most prisons with a developed psychiatric in-reach team and, although not perfect, presents no conceptual difficulty for the community model. But what of the health care wing population?

\section{THE PRISON HOSPITAL WING}

Unlike prisoners with physical illnesses of comparable severity, those developing a serious mental illness are usually moved to the health care wing where they may wait months for transfer to hospital, after a protracted period of referral to local services, assessment, decision-making, seeking a hospital bed at the appropriate level of security and, finally, transfer (Reed \& Lyne, 2000).

Standard 5 of the National Service Framework states:

'Each service user who is assessed as requiring a period of care away from their home should have timely access to an appropriate hospital bed or alternative bed or place, which is in the least restrictive environment consistent with the need to protect them and the public and as close to home as possible'.

Is the prison hospital wing an 'alternative place'? Is a prison hospital wing the least restrictive environment for a mentally ill prisoner charged with shoplifting? Is a wait of months for transfer to hospital 'timely' in accordance with Standard 5 of the National Service Framework?

Prison health care wings are not hospitals, being specifically excluded by the National Health Service Act 1977, and consequently prisoners located there cannot receive medication against their wishes under the Mental Health Act 1983, unlike their counterparts in hospitals in the NHS and independent sector. Treatment can be given only under common law, and this has tended to be interpreted in very narrow fashion so that medication is held in reserve until an emergency (see for more detailed discussion Wilson \& Forrester, 2002). In addition, owing to the lengthy delays in assessment and transfer to hospital, psychiatrists who have worked in prisons will be all too familiar with the uncomfortable position of considering not treating their prisoner patients in case they get well before they have had the opportunity of hospital treatment (Earthrowl et al, 2003). Does this make prison hospital wings suitable 'alternative places' for those in need of a period of 'care away from home'? There is no equivalent of a prison hospital wing anywhere else, and this presents conceptual problems for the community model of mental health care in prisons, and for the principle of equivalence.

\section{WHAT ARE PRISON HOSPITAL WINGS FOR?}

In taking over prison health care the NHS needs to answer the question 'What are the health care wings of prisons for?' Currently they occupy a limbo between the community of the prison and the hospital beds of the NHS and independent sector. Their continued existence means that their occupants remain almost invisible - they would not be so difficult to see if all prisoners awaiting a hospital bed were sent to queue up in their local casualty department. The prison hospital wing is tacitly accepted as an 'alternative place' better to be unwell in a prison hospital wing than in the community. Yet psychiatric professionals working in prisons are unable to treat their patients in equivalent fashion to their patients in hospital (Needham-Bennett \& Cumming, 1995), 
and the prison is not a safe place to wait for a hospital bed (Reed, 2003).

With the introduction of prison psychiatric in-reach teams, the detection of mental illness within prison is much improved and is likely not to be responsible for delays in transfers to hospital (although a key performance indicator of prison psychiatric services will be the transfer times). Either more secure psychiatric hospital beds are needed in Britain or prison health care wings need major changes. Will the takeover by the NHS provide an increased number of beds outside the prison? It is difficult to see how. This is a longstanding problem - Broadmoor Hospital opened as an Asylum for the Criminally Insane in 1863 to remove mentally ill prisoners to hospital. Over 100 years later, epidemiological surveys continue to demonstrate the high prevalence of severe mental illness in prisons (Singleton et al, 1998).

\section{PRISON HOSPITAL WINGS AS HOSPITALS}

Bringing prison hospital wings, suitably staffed and equipped, under the aegis of the Mental Health Act 1983 might provide the best route to equivalence of care for prisoners. Such prisoner-patients thus would be 'doubly detained' under the Mental Health Act and the criminal law. This would be the same as patients currently detained in hospital under Sections 35, 36, 38, 47 and 48 of the Mental Health Act 1983 in England and Wales, and thus should not present additional legal problems. This would eliminate the interminable and unacceptable waiting for NHS hospital beds and would allow compulsory treatment in prison where needed, in line with the treatment of mental disorders outside the prison. Psychiatrists traditionally have opposed this on the grounds that mentally ill prisoners would get second-class treatment, although it is hard to think that what happens at present is first class. However, there are signs that they are beginning to reconsider this difficult issue, at least in terms of advocating more liberal interpretations of the common law relating to medical treatment in prisons (Wilson \& Forrester, 2002; Earthrowl et al, 2003). Treatment under common law would not bring with it the statutory protections of the Mental Health Act, including regular inspections by the Mental

SIMON WILSON, MRCPsych, HM Prison Brixton, Jebb Avenue, Brixton, London SW2 5XF, UK. Tel: 0208588 6058; fax: 0208588 6295; e-mail: dr_simon_wilson@yahoo.co.uk

(First received 4 March 2003, final revision 20 June 2003, accepted 25 June 2003)

Health Act Commission. These are essential for ensuring equivalence of clinical care. Making more use of the common law would simply maintain the status quo by fudging the critical question of what prison hospital wings are for, and certainly does not amount to equivalent care.

It might be argued that such treatment would not be equivalent to the treatment of physical disorders in prisoners, with the example of the failure of surgical units within prisons in mind (Home Office, 1990). This would be to misinterpret the principle of equivalence, however. The care of prisoners with mental illnesses should be equivalent to the care of non-prisoners with mental illnesses, not to the care of prisoners with physical disorders. However, what it does illustrate is the need for more than simply a change in legislation to provide equivalent care $-\mathbf{a}$ properly multidisciplinary team of trained staff will be needed with proper facilities, and a varied and productive range of therapeutic activities for patient-prisoners. This will not be an easy task, but it is perhaps not so different from the similar struggles going on in many inner-city general psychiatry inpatient settings. What mentally ill prisoners require are adequately equipped and staffed hospital facilities, whether inside or outside the prison walls (Council of Europe, 2002), something that they do not yet have.

There is a broader moral and ethical dilemma hidden here that I think is related to the very different services provided by general and forensic psychiatry. Prisoners transferred to general psychiatric wards normally will have their mental illnesses treated rapidly (weeks to months) before discharge to the community or back to prison. Those transferred to forensic wards are likely to remain in hospital for months to years, having not just their mental illnesses treated but also more offence- and insight-related work. The stark differences in these models of service provision would be highlighted further by any implementation of the changes proposed in this paper. Perhaps the new prison hospital wings would function more like a general psychiatric intensive care ward than a medium secure unit or high secure hospital?
The principle of equivalence that guides the ethos of prison health care delivery relies on a model of the prison as a community, with prisoners receiving primary care and specialist out-patient services within the prison. This model breaks down with prison hospital wings that have no equivalent outside the prison. The current lack of treatment facilities and a clear legal framework for the treatment of prisoners with severe mental illnesses within prison hospital wings, and the unacceptable delays in hospital transfers, make the status quo unacceptable. Without more secure hospital beds in the NHS or independent sector, prisoners with severe mental illnesses are far from receiving equivalent care. Is it not time to reconsider what prison hospital wings are for? Is it not time to enable psychiatrists who work in prisons to treat their patients there equivalently to their patients in hospital? The Department of Health's taking over of prison health care provides an excellent opportunity to re-examine critically the provision of mental health care in prisons.

\section{DECLARATION OF INTEREST}

None.

\section{ACKNOWLEDGEMENTS}

I am grateful to Alec Buchanan and an anonymous assessor for helpful criticism of earlier drafts of this paper.

\section{REFERENCES}

Council of Europe (2002) Report to the Government of the United Kingdom on the visit to the United Kingdom carried out by the European Committee for the Prevention of Torture and Inhuman or Degrading Treatment or Punishment from 4 to 16 February 200I. CPT/Inf (2002) 6. Strasbourg: Council of Europe.

Department of Health (1999) National Service Framework for Mental Health. London: Department of Health.

Earthrowl, M., O'Grady, J. \& Brimingham, L. (2003) Providing treatment to prisoners with mental disorders: development of a policy. Selective literature review and 
expert consultation exercise. British Journal of Psychiatry, 182, 299-302.

Health Advisory Committee for the Prison Service (1997) The Provision of Mental Health Care in Prisons. London: Prison Service.

HM Prison Service \& NHS Executive (1999) The

Future Organisation of Prison Health Care. Report by the Joint Prison Service and National Health Service Executive Working Group. London: Department of Health.

Home Office (1990) Report of an Efficiency Scrutiny of the Prison Medical Service. London: Home Office.
Home Office (1991) Custody, Care and Justice: the Way Ahead for the Prison Service in England and Wales (Cm 1647). London: HMSO.

Needham-Bennett, H. \& Cumming, I. (1995) Waiting for a disaster to happen. BMI, 3II, 516-517.

Reed, J. (2003) Mental health care in prisons. British Journal of Psychiatry, 182, 287-288.

Reed, J. \& Lyne, M. (2000) Inpatient care of mentally ill people in prison: results of a year's programme of semistructured inspections. BM], 320, I03I-1034.
Singleton, N., Meltzer, H. \& Gatward, R. (1998) Psychiatric Morbidity among Prisoners in England and Wales. London: Stationery Office.

Smith, R. (1984) Prison Health Care. London: British Medical Association.

Wilson, S. \& Forrester, A. (2002) Too little, too late? The treatment of mentally incapacitated prisoners. Journal of Forensic Psychiatry, 13, I-8. 